\title{
POR UNA CRONOLOGÍA HISTÓRICA SOBRE EL ŠARQ AL-ANDALUS (S. XIII)
}

\author{
Por \\ EMILIO MOLINA LÓPEZ
}

Hace algunos años, cuando nos interesamos por la historia del SE peninsular, con especial incidencia en el marco histórico del siglo XIII, -objeto que fue también de nuestra tesis doctoral, Murcia y El Levante Español en el siglo XIII a través de la correspondencia oficial, personal y diplomática. Edición, estudio y valoración de los fragmentos históricos contenidos en el manuscrito árabe escurialense n. ${ }^{\circ} 520$ (Granada, 1977) - , advertíamos, dada la extrema complejidad del período estudiado, la necesidad de sintetizar y estructurar cronológicamente el variado material, fuentes y bibliografía, allí utilizado.

Por tratarse de una etapa histórica que no habia recibido la necesaria atención por parte de la moderna investigación y por carecer asimismo de una cronología -siempre útil y habitual para otros periodos, aunque en ningún caso sean lo suficientemente precisas-. por todo ello, nos ha parecido justificada esta iniciativa que ahora presentamos.

No pocas dificultades ofrece la elaboración de una cronología histórica. A ésta se suman, además, las inherentes a un marco temporal tan reducido (1223-1266), así como las de la complejidad de los acontecimientos que en él se desarrollan. Es por ello por lo que la información suministrada tanto por las fuentes árabes como cristianas resulta, con frecuencia, imprecisa, cuando no contradictoria.

Nuestro propósito, al elaborar la presente cronología, no es otro que el de sintetizar medio siglo historico-político del Islam en al-Andalus, y en especial, del Levante y SE peninsular, así como el de establecer un orden coherente en las datas suministradas por las fuentes, hecho que no advertimos en una gran parte de la bibliografía moderna dedicada a este período.

Son varios los criterios de elaboración que concurren en esta iniciativa. En primer lugar, se respetan, cuando no hay contradicciones, las fechas suministradas por las fuentes árabes y cristianas; cuando esto último se produce, así lo hacemos constar. Ocurre también con frecuencia que ambos medios de información al incidir sobre un mismo acontecimiento, alguno de ellos silencia la fecha precisa; en uno y otro 
caso hacemos la respectiva conversión y cálculo más ajustado a las datas citadas. $Y$, por fin, un buen número de noticias de esta cronología carece de fecha; en tales circunstancias los sucesos han sido ordenados conforme a nuestros propios criterios históricos, de los cuales nos hacemos responsables en cada caso. En todo momento, el hilo conductor de esta cronología han sido las fuentes árabes, sin que por ello hayamos eludido, cuando lo hemos considerado conveniente, la consulta de las fuentes cristianas.

Todas las fechas que no aparecen expresamente citadas en las fuentes van entre corchetes.

$Y$, por último, para el desarrollo histórico de los acontecimientos citados en esta cronología, véase, principalmente, E. MOLINA LOPEZ, "Murcia en el marco histórico del segundo tercio del siglo XIIl», en Historia de la Región Murciana, III, Ed. Mediterráneo, Murcia 1980, págs. 188-263, fuentes y bibliografía allí mencionadas.

\section{CRONOLOGIA HISTÓRICA}

(S. XIII)

\section{$[614] / 1217$}

Muhammad b. Yúsuf b. Hūd arrebata el castillo de Sanfĩo a los cristianos.

$614 / 1217$

\section{$[619] / 1223$}

Abū Zayd se encuentra a cargo del gobierno de Valencia.

\section{$[620-1] / 1224$}

Muerte del califa almohade Yūsuf́ll al-Mustanşir.

12 dū I-hî̀ŷa $620 / 6$ enero 1224.

'Abd al-Wăhid es elegido califa en Marraquex. Esta designación es mal acogida en al-Andalus.

domingo 13 dū I-hiŷya $620 / 7$ enero 1224

${ }^{c}$ Abd Allāh b. Yacqūb al-Manșūr, al-'Adil, nieto del califa 'Abd al-Wăhid, se subleva en Murcia.

La autoridad de al-'Adil es reconocida por los sayyids almohades españoles.

La autoridad de al-`Ádil no es reconocida por el sayyid Abū Zayd, gobernador de Valencia, Denia, Játiva y Alcira.

Los almohades del Magrib deponen a 'Abd al-Wāhid.

\author{
13 șafar $621 / 6$ marzo 1224 o 24 \\ marzo 1224.
}

șafar 621/marzo 1224 .

șafar $621 /$ marzo 1224

25 Sacbăn 621/noche del martes 11 de septiembre de 1224 . 
Ibn Hūd acuña moneda en Murcia.

Al-Ádil nombra gobernador de Sevilla a su hermano Abū- ¿Ulà.

Al- ${ }^{\circ}$ Adil nombra gobernador de Córdoba a al-Bayyāsī, hermano del gobernador de $\mathrm{Va}$ lencia Abū Zayd.

Al-Bayyāsī se rebela contra al-'Adil y se proclama independiente en Baeza con autoridad sobre Córdoba, Jaén y Quesada.

Al- ${ }^{\complement}$ Addil ataca Baeza.

Al-Bayyāsī pide ayuda a Fernando III.

Córdoba se subleva contra al-Bayyāsĩ por su alianza con Castilla. 621/enero 1224-enero 1225.

[dūl-qa $a^{c}$ da 621 ]/octubre-noviembre 1224.

[dūl-qac da 621]/octubre-noviembre 1224

[d] I-hiŷŷa 621]/noviembre-diciembre 1224.

[d̆ū I-hiŷŷa 621]/noviembre-diciembre 1224.

[du I-hiŷŷa 621]/finales diciembre 1224.

[düul-hiyŷa 621-muharram 622]/finales 1224 y comienzos 1225 .

\section{$[622-623] / 1225$}

Murcia sufre un severo ataque por los cristianos de Cuenca, Huete, Alarcón y Moya.

Al-`ÁAil se traslada a Marraquex y deja como gobernador general de al-Andalus a su hermano Abū l-'QUlà al-Ma'mūn.

Abū Zayd presta vasallaje a Fernando III en Moya. verano $622 / 1225$

[dūl-hiyŷa 622]/noviembre 1225.

[ḍül-ḥîyya 622]/segunda mitad 1225 .

\section{$[623] / 1226$}

Al-Bayyāsĩ sitia Sevilia pero pierde la plaza.

Abū l'-Ul'à comunica a su hermano al'Adil este incidente a través de una carta oficial.

Muerte de al-Bayyāsi en Almodóvar del Río a manos de sus súbditos.
Comienza el cerco a finales de 1225 o comienzos de 1226 .

rabrid 623/marzo 1226 .

verano $623 / 1226$

Al-Ma'mūn se subleva en Sevilla y es reconocido califa.

2 sawwāl 624/15 septiembre 1227.

Al-'Adil muere asesinado en Marraquex.

21 sawwäl 624/martes 4 octubre 1227. 
Los almohades nombran en Marraquex a Yahyà b. al-Nașir califa.

El gobernador de Valencia Abü Zayd reconoce a al-Ma'mūn.

Carta de los habitantes de Valencia reconociendo a al-Ma'mūn.

Ibn Hūd sale de Murcia en dirección a Ricote acompañado de una guarnición de soldados.

Abū Zayd informa a al-M'amün de la toma de Bejís en la frontera de Valencia por las fuerzas aragonesas.
21 šawwäl 624/martes 4 octubre 1227

[Sawwảal 624]/septiembre-octubre 1227

[šawwăl 62]/septiembre-octubre 1227.

[qü I-hiŷŷa 624]/finales 1227 o comienzos 1228

[d̄ū I-hịŷya 624]/finales 1227.

\section{$[625] / 1228$}

Rebelión antialmohade $y$ pro-‘abbāsí de Muhammad b. Yūsuf b. Hūd en Ricote.

Ibn Hūd rechaza un ejército comandado por el gobernador de Murcia Abū Mũsa b. 'Alī b. 'Imrăm.

Victoria de Ibn Hūd sobre las tropas del gobernador de Valencia Abū Zayd.

Ibn Hūd se apodera de Murcia con la ayuda del cadí Abū I-Hasan 'Alī b. Muhammad al-Qasțalii.

La nobleza murciana jura fidelidad a Ibn Hūd. Éste toma el título de al-Mutawakkil 'alà Allăh.

El califa almohade al-Ma'mūn ataca a lbn Hüd en Lorca. Ibn Hūd se repliega en Murcia.

Al-Ma'mūn abandona el cerco de Murcia.

Al-Ma'mūn marcha a Marraquex.

Ibn Hūd acuña moneda en Murcia con el título: amir al-muslimin.
1 de raŷab 625/16 de junio 1228 .

[raŷab-łacbān 625]/junio-julio 1228

[raŷab-కacbån 625]/junio-julio 1228.

[Šacbān-ramaḍăn 625]/finales de julio y comienzos de agosto de 1228 .

1 ramaḍann 625/4 agosto 1228 .

[Šawwăl 625]/segunda mitad 1228. [కawwāl 625]/otoño 1228 o [క̌awwãl 6261 otoño 1229.

đũ l-qa'da 625/octubre 1228 o dūI-qac da 626/octubre 1229.

$626 / 1228-1229$

$[625-626] / 1228-1229$

'Azīz. b. Jațtāa es nombrado por Ibn Hūd gobernador de Murcia.

[muharram-șafar 626]/finales 1228comienzos 1229 . 
Rebelión de Abū Ŷamil Zayyăn b. Mardanīs en Onda contra el gobernador almohade de Valencia Abū Zayd. Reconoce la autoridad 'abbãsí. [muharram-șafar 626]/finales diciembre 1228-comienzos enero 1229.

\section{$[626] / 1229$}

Abū Zayd, para mayor seguridad, se retira a Segorbe.

Zayyān entra en Valencia.

Abū Zayd pacta con Jaime I.

Los gobernadores de Denia y Alcira, Abū Zakariyya $\bar{a}^{c} b$. Sacd y Abū Yahyà b. 'AbT Sulțán b. 'Abì I-Haŷỹây b. Sa'd, reconocen a lbn Hūd.

El gobernador de Játiva Ahmad b. Tsà alJazraŷī reconoce a Ibn Hũd. Éste acuñará moneda en plata en esta ciudad.

Granada, en nombre de su gobernador Abũ I-Hasan Sahl b. Mălik, se somete a Ibn Hüd.

Almería en nombre de su gobernador Muhammad b. Yahyà al-Ramìmī, se somete a Ibn Hūd.

Málaga, en nombre de su gobernador 'Abd Allāh b. Dị l-Nūn, se somete a lbn Hūd. Éste acuñará moneda de plata en esta ciudad.

Córdoba se somete a Ibn Hūd. Éste acuñará moneda en esta ciudad.

Sevilla, en nombre de su gobernador, Abu Bakr b. al-Bannā, se somete a lbun Hūd. Éste acuñará moneda en esta ciudad.

Valencia, en manos de Zayyān, niega su autoridad a Ibn Hūd.

Ibn Hūd intenta tomar la plaza de Valencia. Abandona el proyecto.

Abū I-Hasan 'Adūd al-Dawla, hermano de Ibn Hūd, envía carta de felicitación a los sevillanos por adherirse a lbn Hũd. [şafar 626]/primeros días de enero de 1229.

26 șafar 626/24 enero 1229 .

[27 ŷumảdà |l 626]/29 abril 1229 .

primer tercio Sawwal 626/1-10 septiembre 1229.

[కawwăl 626]/septiembre 1229.

[Šawwăl 626]/septiembre 1229.

[sawwăl 626]/septiembre 1229.

[Sawwål 626]/septiembre 1229.

[du |-qa'da 626]/septiembre-octubre 1229 .

11 dü I-ḥiŷŷa 626/31 octubre 1229.

[șafar-కawwảl 626]/enero-septiembre 1229 .

[şafar-šawwảl 626]/enero-septiembre 1229 .

17 dū |-hî̀ŷa $626 / 6$ noviembre 1229. 
Ibn Hūd envía una embajada a Bagdad para reconocer la autoridad del califa 'abbā sí.

Ceuta, en nombre de su gobernador al-Gustī, se somete a Ibn Hūd. Ibn Hūd sufre una derrota en Jerez por las tropas de Fernando III. [muharram-șafar 627]/finales 1229 comienzos 1230 .

$627 / 1230$

$[627] / 1230$.

\section{$[628] / 1231$}

Algeciras y Gibraltar se someten a Ibn Hūd. Ion Hūd sufre una derrota en Mérida y Badajoz por Alfonso IX de León.

Se informa a al-Ma'mün de la toma del castillo de Cullera en la jurisdicción de Alcira. raŷab 628/mayo 1231

$628 / 1231$

12 Sacbān 628/15 junio 1231.

$[629] / 1232$

Ibn Hūd intenta tomar Valencia.

$[629] / 1232$

Sublevación de Muhammad b. Yũsuf $b$. Nașr b. al-Ahmmar en los alrededores de Jaén.

Las órdenes militares de Alcántara y Santiago atacan la plaza de Trujillo. Se tomará definitivamente en 1233 .

$[629] / 1232$.

Baza y Guadix se unen a Muhammad b. Nașr b. al-Aḥmar.

Al-Ma'mūn muere en el Magrib.

Al-RaŠid es proclamado califa.

La ciudad de Úbeda se rinde a Fernando III. La rendición finalizó en julio de 1233 .

El califa 'abbåś escribe una carta a lbn Hüd reconociéndole como emir de alAndalus. (2).

viernes 16 ramaḍann $629 / 18$ abril 1232.

[629]/1232.

29 dū l-hiŷya $629 / 16$ octubre 1232. - 30 dū l-hiyyya $629 / 17$ octubre 1232.

30 du I-hiŷya $629 / 17$ octubre 1232.

rabr | 630/diciembre 1232.

dū l-qa ${ }^{c}$ da 629/agosto-septiembre 1232.

$[630] / 1233$

Ibn Hūd pierde la plaza de Trujillo.

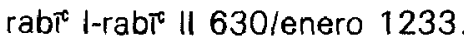

Abū Zayd cede todas las rentas que tenía en el territorio valenciano a Jaime l en la ciudad de Teruel.

[16 rabr $\|$ 630]/30 enero 1233. 
Jaén renuncia a la autoridad de lbn Hūd y se somete a Ibn al-Ahmar.

El gobernador de Murcia Ibn Jațțāb informa a Ibn Hūd de la toma de al-Tarka.

Cordoba renuncia a la autoridad de Ibn Hūd $y$ se une a Muhammad b. Nașr b. Al-Ahmar.

Cordoba vuelve a reconocer la autoridad de Ibn Hūd.

Sevilla renuncia a la autoridad de Ibn Hūd y proclama su independencia, protagonizada en la familia de los Banú Baŷỹt.

Ion Hud asedia Sevilla.

Fernando III reconquista la plaza de Úbeda.

Ion Hüd concierta una tregua con las fuerzas castellanas, a condición de pagar 1.000 dinares diarios.

Ibn Hūd sufre una derrota en Aznalfarache; en complot, los sevillanos e Ibn al-Ahmar son la causa de esta adversidad. Ibn Hud huye en barco.
$630 / 1233$

$[630] / 1233$

$630 / 1233$

al cabo de unos meses dentro del año 1233.

$[630] / 1233$

$[630] / 1233$.

[630-631]/julio 1233

631/octubre-noviembre 1233.

$[630-631] / 1233$

\section{$[631-632] / 1233$}

Los sevillanos reclaman de nuevo la autoridad de lbn Hũd. Éste nombra como gobernador de Sevilla a su hermano Abü I-Nā-

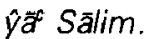

Sublevaciónde Ibn Mahfút en Niebla.

Ibn al-Ahmar se somete a la obediencia de Ibn Hüd.

Ibn al-Ahmar es reconocido "rey" de Jaén, Arjona y Porcuna.

Cadiz es atacada por las tropas cristianas.

Ibn Hūd recibe la carta del califa 'abbasí por la que se le nombra emir de al-Andalus y le son añadidos los títulos de Muy̆āhid alDin y Sayf amir al-muslimin.
631/1233-1234 o 632/1234-1235. Yumādà /I 631/15 marzo-12 abril 1234.

Sawwāl 631/junio-julio 1234.

[Sawwāl 631]/junio-julio 1234.

[dū I-hiŷya 631]/septiembre 1234.

$631 / 1234$

[632-633]/1234-1235

Ibn Hūd lee la carta del califa de Bagdad a los granadinos. [rabĩ ||-yumådà I| 632//primeros meses 1235 . 
Carta de los habitantes de Játiva felicitando a Ibn Hüd por el reconocimiento recibido de Bagdad.

[rabic \|-ŷumảdà \| 632]/primeros meses 1235.

\section{$[633-634] / 1236$}

Ibn Hūd pierde la plaza de Córdoba.

Abū Zayd se convierte al cristianismo. rabri |I-ŷumãdà || 633/enero 1236 o 23 Šawwăl 633/29 junio 1236.

[rayab-šacbản 633]/22 abril 1236.

$[634-635] / 1237$

Ibn Hūd envía una carta a los gobernadores de al-Andalus recordándoles su compromiso de fidelidad al califa 'abbåsí, la buena administración de la Hacienda y la defensa de las fronteras.

Muḥammad b. Nașr b. al-Ahmar hace su entrada en Granada.

Zayyān es derrotado por Jaime I en la batalla de Aniša. Muere en la contienda Sulaymān b. Müsà b. Sälim.

Conquista de Onda por Jaime I.

Carta de los habitantes de la ciudad de Játiva a Ibn Hūd reconociendo su autoridad y solicitando que declara príncipe heredero a su hijo al-Wātiq. Se acuñará moneda de plata a nombre de al-Wātiq como príncipe heredero.

Carta de los habitantes de Alcira reconociendo como sucesor de lbn Hūd a su hijo al-Wātiq .
[24 Y̧umãdà I 634]/24 enero 1237.

ramaḍann 634/mayo 1237 o ramaḍān 635/mayo-junio 1238.

10 dū l-hîŷya 634/4 agosto 1237. [634]/1237.

$[634] / 1237$.

$[634] / 1237$.

\section{[635-636]/1237-1238}

Muere asesinado en Almería Muhammad b. Yūsuf b. Hūd, a manos de su gobernador al-Ramimî. Éste huye a Ceuta y Túnez. AlWātiq queda como sucesor. Éste acuñará moneda a su nombre en Murcia.
24 y̌umādà $1635 / 13$ enero 1238 o finales de 1237.

\section{$[635-636] / 1238$}

Se inicia el cerco de Valencia por Jaime I. Málaga jura obediencia a Ibn al-Ahmar.

Se acuña moneda de oro en Játiva a nombre de al-Wātiq lunes 5 ramaḍann 635/21 abril 1238 . $636 / 1238$

$636 / 1238$ 
A la muerte de lbn Hūd Sevilla reconoce la soberanía del califa almohade al-Rašĩd.

A la muerte de lbn Hũd Málaga se hace independiente con 'Abd Allăh b. Dì I-Nūn.

A la muerte de lbn Hūd Jaén y Granada se unen a Ibn al-Ahmar y reconocen la autoridad de al-Rašid.

Ibn al-Ahmar. entra en Almería.

Reconocimiento de la autoridad de al-Rašid por Sevilla y Ceuta.

Zayyān envía a Túnez una embajada reconociendo la autoridad del emir Abū Zakariyyă Yahyà, solicitando ayuda militar. A la cabeza de la expedición marcha lbn alAbbār.

Ibn al-Abbãr declama su casida en sin en Túnez.

L.as naves tunecinas se presentan en la playa de Valencia. No pueden desembarcar a causa del bloqueo.

Al-Wātiq es destronado en Murcia. (Parece ser que el gobernador de Murcia, como tutor de al-Wătiq, era un hermano de lbn Hūd Ilamado 'Âlī b. Yūsuf b. Hūd).

'Azīz b. Jațțāb es proclamado en Murcia. Los murcianos le envían una carta de reconocimiento.

Retirada de las naves ḥafšles de la playa de Valencia ante la imposibilidad del desembarco.

Jaime I conquista la ciudad de Valencia. Firma el acta de capitulación Ibn al-Abbār por parte de Zayyān.

Los murcianos ante la incapacidad para el gobierno de Ibn Jațtáb ofrecen la capital a Zayyān.
$636 / 1238$.

$636 / 1238$

$636 / 1238$.

sawwăl 635/mayo-junio 1238.

sawwal $635 / 17$ mayo-14 junio 1238.

[కawwål-d̄ū I-ḥiŷya 635]/mayo-junio 1238.

4 muharram 636/17 agosto 1238 .

4 muḥarram 636/17 agosto 1238 .

4 muharram $636 / 17$ agosto 1238 .

4 muharram 636/17 agosto 1238 .

[12 muharram 636$] / 25$ agosto 1238.

martes 17 șafar $636 / 28$ septiembre 1238.

[şafar-rabr $\left.{ }^{\complement} \mid 636\right]$ /octubre 1238.

$[636-637] / 1238-1239$

Ibn Jațtăb organiza campaña contra los cristianos. abril 1239 . 
Llegada de Zayyān a Murcia. Asume el gobierno de la ciudad y proclama la soberanía ḥafșí.

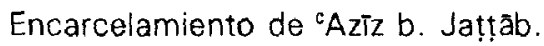

Ejecución de Ibn Jațtāb.

Zayyān pone en libertad a al-Wāția.

Zayyān envía un emisario a Túnez para expresar su reconocimiento a dos hafșíes. El embajador fue $A b u ̄{ }^{C} A b d$ Allāh b. Abi Hă rit.

Abū Zakariyyāe Yahyà le envía ayuda y le reconoce como emir del Levante a Zayyân.

Una flota de Abū Zakariyyāc Yahyà fondea en el puerto de Cartagena. Llegan a dicho puerto delegaciones de todo el Levante. Se reciben cartas reales del emir hafșí para los habitantes de Murcia, Játiva, Orihuela, Lorca y Alcira.

Abū Y̌acfar b. 'Isām se proclama independiente en Orihuela. viernes 15 ramaḍan $636 / 21$ abril 1239 o sábado 16 ramaḍăn 636/22 abril 1239 .

domingo 17 ramaḍān 636/23 abril 1239.

19 ramadăn $636 / 25$ abril $1239 \circ 20$ ramadản $636 / 26$ abril 1239 o lunes 26 ramad̆an $636 / 2$ mayo 1239.

[ramaḍann-ławwăl 636]/abril-mayo 1239.

ramad̄an-కawwā! 636/abril-mayo 1239.

[కawwāl-dū $\mid-q a^{c} d a \quad 636$ ]/mayo-junio 1239 .

[rabi $\|$ | 637]/noviembre 1239.

[y̌umādà | 637]/diciembre 1239.

\section{$[637] / 1239-1240$}

Ibn al-Ahmar reconoce la autoridad del califa almohade al-Rasīd.

a partir del 636/1239 hasta el $640 / 1242$.

\section{$[637-639] / 1240-1242$}

Zayyān intenta prestar vasaliaje a Castilla.

Emigración musulmana del Levante y Murcia al Norte de Africa.

Muhammad b. Hūd Bahăa al-Dawla restablece en Murcia la dinastía de los Banũ Hüd y expulsa a Zayyān.

Zayyãn se retira a Alicante o a Luchente. donde permanecerá hasta la primavera-verano de 1243 .
$[638] / 1240$.

21 కacbān $637 / 17$ marzo 1240.

[ŷumạdà II 637-raŷab 638]/finales 1240-comienzos 1241.

[ŷumãdà || 637-raŷab 638]/finales 1240-comienzos 1241. 
Bahāc al-Dawla impone su autoridad sobre Abū Y̌ $a^{c}$ far b. Ișām.

Lorca se proclama independiente con $\mathrm{Mu}$ h. hammad b. 'Alī b. Aḥtĩ.

Bahāc al-Dawla intenta prestar vasallaje a Castilla.

Muerte del califa al-Rašĩd.

Los arraeces de Crevillente, Elche, Alhama, Aledo, Ricote, Cieza e incluso Orihuela, no obedecen a Bahăc al-Dawla, aunque reconocen su soberanía. [ŷumādà II 637]/a partir de 1240.

[ŷumādà || 63்-ŷumādà || 638]/entre 1240-1241.

[ŷumādà || 638-ŷumādà || 639]/entre 1241-1242.

viernes 10 ŷumādà || 640/5 diciembre 1242 .

[637-640]/entre 1240 y 1243.

\section{$[640-641] / 1242-1244$}

Primer contacto de emisarios de Bahăc alDawla y Alfonso en Toledo, para tratar de la capitulación de Murcia. Interviene en las

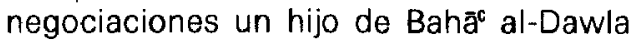
llamado Ahmad.

Murcia presta vasallaje al infante Alfonso en Alcaraz. No todas las ciudades aceptan la decisión. Participan Crevillente, Alhama, Cieza, Alicante, Orihuela, Aledo y Ricote. Los murcianos expulsan a al-Wātiq.

La plaza de Murcia es ocupada por el infante Alfonso.

Se niegan a la ocupación Alicante, Orihuela, Aledo y Elche.

Asegurada la paz en Murcia, Alfonso vuelve a Toledo.

Alfonso vuelve a Murcia para reforzar las plazas ocupadas. [కa'bān 640]/finales febrero 1243.

10 sawwăl $640 / 2$ abril 1243.

[Sawwāl 640]/abril 1243.

[d̆ I-qa ${ }^{c}$ da 640]/viernes 1 mayo 1243.

[muharram 641]/junio 1243.

$\left[\mathrm{rabl}^{\mathrm{C}} \mid 641\right]$ /agosto 1243 .

[raŷab 641]/finales 1243 y primeros meses de 1244.

\section{$[641-642] / 1243-1245$}

Las plazas de Cehegín y Caravaca se entregan a Martín Martínez, maestre del Temple.

Tratado de Almizra.

Conquista de Mula por Alfonso.
[641]/1243-1244.

[16 Sawwāl. 641]/28 marzo 1244.

[dū l-hîŷa 641]-[rabr । 642]/primavera-verano 1244. 
Ef $r a^{c} \overline{i s}$ de Lorca entrega la ciudad al infante Alfonso.

Presencia del ex-gobernador almohade de Valencia Abū Zayd en Murcia. [d̄u I-qa da 641 -muharram 642]/ entre el 15 de abril-28 junio 1244.

[rabi || 642]/28-29 septiembre 1244.

\section{$[642-643] / 1245$}

Conquista de Cartagena por el infante Alfonso.

[muḥarram 643]/primavera 1245.

\section{$[643-644] / 1246$}

Zayyān huye a Túnez. Muere en 12691270 .

[644]/1246.

Conquista de Jaén.

du l-qa ${ }^{c}$ da 643/febrero-marzo 1246 .

Sevilla reconoce a los hafșíes. Envian a Túnez al visir "Umar b. al-Yadd.

643/mayo 1245-mayo 1246

Se acuña moneda en Murcia bajo el gobierno de Bahă $\bar{a}^{c}$ al-Dawla a nombre del califa 'aboāsí. (La moneda es de tipo hafșí).

$644 / 1246$

\section{$[644-645] / 1247$}

Llega a Sevilla Abū Färiš, delegado de Abū

Zakariyyāc.

644/mayo 1246-mayo 1247

Ibn Mahfüt se rinde.

[rabĩ || 645]/agosto 1247.

\section{$[645-646] / 1248$}

Conquista de Játiva por las fuerzas aragonesas.

[muharram 646]/primavera 1248.

Conquista de Sevilla por las fuerzas castellanas.

Šacbān 646/diciembre 1248.

$[646-647] / 1249$

Se acuña moneda bajo el gobierno de Bahăc al-Dawla a nombre del califa 'abbāsí (la moneda es de tipo hafșí).

$646 / 1248-1249$.

$[647-649] / 1250-1251$

Presencia de Abū Zayd en Murcia.

$[646] / 1251$

$[649-650] / 1252-1253$

Se acuña moneda en Murcia bajo el gobierno de Bahăc al-Dawla a nombre del califa 'abbāsí. (La moneda es de tipo almohade) 
$[651] / 1254$

Ibn al-Ahmar presta vasallaje a Alfonso $\mathrm{X}$.

[651]/1254.

[652-654]/1255-1257

Se acuña moneda en Murcia bajo el gobierno de Bahă $\bar{a}^{c}$ al-Dawla a nombre del califa 'abbāsí. (La moneda es de tipo almohade)

$654 / 1256$

[655-656]/1258-1259

Se acuña moneda en Murcia bajo el gobierno de Bahă al al-Dawla a nombre del califa 'abbăsí. (La moneda es de tipo almohade)

656/1258-1259.

$[657-658] / 1259-1260$

Muerte de Muhammad b. Hūd Bahăc alDawla.

$[657-658] / 1259-1260$.

$[658-661] / 1260-1263$

Abū Ŷacfar b. Muhammad b. Hūd hijo de Bahãc al-Dawla se hace cargo del gobierno de Murcia. Este aparece confirmando documentos cristianos hasta 1263.

[658-661]/1260-1264.

Presencia de Abu Zayd en Murcia.

$660 / 1262$.

[661-662]/1263-1264

Muerte de Abū $\hat{Y} a^{c} f a r b$. Muhammad b. Hūd.

[antes del 29 ŷumādà II 662]/antes del 15 abril 1264.

Le sucede su hijo Muhammad b. Abi $\hat{Y} a^{c}-$ far b. Muhammad b. Hūd, quien aparece confirmando documentos cristianos hasta 1264.

Ibn al-Ahmar reanuda las hostilidades con Alfonso $X$. Se inicia la revolución mudéjar.

Al-Wātiq envía al Papa una delegación para manifestarle los malos tratos a que son sometidos los musulmanes murcianos.

[después de ŷuāà $\|$ y antes de Šacbãn 662]/después del 15 de abril y antes del 5 de junio 1264 .

șafar-raŷab 662/primera mitad de 1264.

[șafar-raŷab 662]/primera mitad de 1264. 
Al-Wãtiq se hace cargo del gobierno de Murcia, rompe el vasallaje con Castilla y destrona a Muhammad $b$. Abi $\hat{Y} a^{c} f a r b$. Muhammad b. Hūd.

Sublevación mudéjar en Murcia sostenida por iniciativa de los granadinos.

No participa en la rebelión murciana el rāts de Crevillente Ahmad b. Hūd.

Al-Wātiq, ante la presión castellana y aragonesa, pide ayuda a Ibn al-Ahmar.

Ibn al-Ahmar envía a 'Abd Allăh b. Abi Ašqilüla, quien ocupa el gobierno de Murcia.
[29 șafar 662-11 rabĩ l 663]/1264.

[entre el 13 de raŷab-2 కac băn $6621 /$ después del 19 de mayo y antes del 5 de junio de 1264

[29 șafar 662-11 rabi +663$] / 1264$.

[ramaḍān-dū I-hîŷya 662 y muḥarram-șafar $663 \mathrm{~J} / \mathrm{segunda}$ mitad 1264.

[șafar-rabr | 663]/finales 1264 primeros meses de 1265 .

\section{$[663-664] / 1265$}

Primera expedición militar contra Murcia a cargo del infante Pedro, hijo de Jaime 1.

Segunda expedición militar contra Murcia a cargo del infante Pedro.

'Abd Allāh b. 'Alī b. Asquilüla abandona el gobierno de Murcia. En su camino hacia Granada es asaltado por fuerzas aragonesas.

Al-Wãtiq se ocupa por tercera vez del gobierno de Murcia.

El infante Pedro se encuentra en Orihuela.

Tratado en Alcalá Real concertado entre lón al-Ahmar y Alfonso $X$.

Al-Wātiq, ante la traición de los granadinos, se dirije a Santisteban del Puerto para prestar vasallaje a Alfonso $X$.

Alfonso $X$ concede a al-Wătiq el castillo de Yusr (Fortuna).

La población de Lorca resiste la presión cristiana. Su defensor será Muhammad b. 'Alī b. Muhammad b. 'Alī b. Ahlit.

Fracasa la rebelión mudéjar en Orihuela.
[Ŷumādà II-râyab 663]/abril 1265. E) 25 abril se encontraba en Alicante.

[ramaḍān 663]/junio 1265.

[ramaḍăn 663]/junio 1265.

[ramaḍãn 663]/junio 1265.

[3 ramaḍan 663]/19 junio 1265 .

[dū l-qa ${ }^{c}$ da 663]/finales de agostocomienzos de septiembre 1265.

[10-15 dū l-qa da 663]/finales octubre-comienzos noviembre 1265 .

[muharram-șafar 664]/octubre-noviembre 1265 .

[șafar 664]/finales 1265.

[șafar 664]/finales 1265 . 
Alfonso $X$ socorre la plaza de Lorca. Protección de Huescar y Taibilla.

Alicante y Almansa persisten en la rebelión. Alfonso $X$ pierde Galera y Moratalla.

Alfonso $X$ envía desde Sevilla una flota al puerto de Cartagena en ayuda de los cristianos asentados en Murcia. Levantan dos fortalezas que suponen los puestos más avanzados del frente castellano hacia la capital: la Asomada en el campo de Cartagena y Tabala al este del cerro del Castellar. Jaime l interviene en la reconquista de Murcia.

Jaime I pasa por Játiva en dirección a Murcia.

Jaime I marcha de Játiva a Biar, límite meridional del reino murciano. Se le unen fuerzas castellanas.

La plaza de Villena se somete a Jaime I, pero no definitivamente hasta nueve meses más tarde.

Jaime I entra en Elda.

Jaime I se dirige a Petrel.

Jaime I entra en Monforte.

Jaime I entra en Alicante.

Jaime I ocupa Elche.

Orihuela capitula pacíficamente ante Jaime I.

En Orihuela se presenta ante Jaime I el hijo de Bahāa al-Dawla, Ahmad b. Hūd, para entregarle la villa de Crevillente.

En Orihuela le llegan noticias a Jaime I de que una expedición militar de Granada marcha en ayuda de los murcianos. [șafar 664]/finales 1265 .

[șafar 664]/finales 1265 .

[șafar 664]/finales 1265 .

[șafar 664]/finales 1265 .

[muharram-șafar 664 ]/noviembre 1265.

[24-27 muharram 664]/5-8 noviembre 1265 .

[29-30 muharram 664]/10-12 noviembre 1265 .

[1-4 șafar 664]/12-15 noviembre 1265.

[4-6 șafar 664]/15-17 noviembre 1265

[6-7 șafar 664$] / 17-18$ noviembre .1265

[7-8 șafar 664]/18-19 noviembre 1265

[10 șafar 664]/21 noviembre 1265.

[16-19 safar 664]/últimos días noviembre 1265 .

[18-21 șafar 664]/finales noviembrecomierizos diciembre 1265 .

[18-21 șafar 664]/finales noviembrecomienzos diciembre 1265 .

[18-21 șafar 664]/finales noviembrecomienzos diciembre 1265 . 
Jaime I sale al paso de la expedición militar granadina y la rechaza en Buznegra (Voz negra). Los huidos se refugian en Alhama.

Jaime I marcha a Alcantarilla. Se reúne el Consejo para decidir la toma de Alhama. Se aplaza esta deliberación.

Jaime I vuelve a Orihuela.

Llegan noticias a Orihuela de que las fuerzas granadinas intentan pasar de Alhama a Murcia.

Jaime I marcha a Alcaraz para entrevistarse con su yerno Alfonso.

Jaime I, a su regreso de Alcaraz, pasa por Villena, Monforte $y$ Elche.

Jaime I llega a Orihuela.
[18-25 șafar 664]/finales noviembrecomienzos diciembre 1265.

[20-25 șafar 664]/primeros días diciembre 1265 .

[23-25 șafar 664]/4-6 diciembre 1265.

[23-25 safar 664]/4-6 diciembre 1265.

[27 șafar 664]/8 diciembre 1265 . Permanecerá hasta el 19 del mismo mes.

19-11 rabr | 664]/entre el 19 de diciembre y el 21 del mismo mes de 1265.

[11 rabr l-23 rabic | 664]/21 diciembre 1265. Permanecerá hasta el 1 de enero de 1266.

\section{$[664-665] / 1266$}

Jaime I sale de Orihuela con dirección a Murcia.

[23 rabr | 664]/2 enero 1266 .

Jaime I inicia el cerco de Murcia.

[26 rabr | 664 ]/5 enero 1266 .

Jaime I recibe las primeras delegaciones de emisarios murcianos para tratar la capitulación de la capital. Interviene como representante responsable de la plaza el visir Abü Bakr b. Abĩ Wadḍăh.

[11 rabi || 664]/20 enero 1266 .

Segunda entrevista de los notables murcianos con Jaime $\cdot 1$.

[14 rabr $\| 664] / 23$ enero 1266.

Tercera entrevista. Se concierta la capitulación de la capital.

Los musulmanes murcianos evacúan el Qașr al-Kabïr.

[17 rabi $\left.{ }^{\complement} \| 664\right] /$ martes 26 enero 1266.

[20 rabr $\| 664] /$ viernes 29 enero 1266.

Las fuerzas aragonesas ocupan la fortaleza.

[21 rabri $\|$ 664]/sábado 30 enero 1266 . 
Abū Bakr se queja de que las huestes aragonesas penetran en la ciudad y roban los bienes de sus habitantes.

Jaime I entra en la plaza y sube directamente al Alcázar. Efectúa las particiones de la ciudad.

Entrada oficial de las fuerzas aragonesas en Murcia.

Los musulmanes murcianos se retiran al barrio de al-Rašāqa.

Los musulmanes murcianos prestan obediencia a Alfonso $X$ en carta fecha en

Alfonso $X$ nombra rey de Murcia a Abū ${ }^{c}$ Abd Allāh Muhammad b. Hūd.
[21 rabi || 664]/noche del sábado 30 enero 1266 .

[22 rab $r^{\leftarrow} \|$ 664]/domingo 31 enero 1266.

[24 $\mathrm{rabr}^{\circ}$ \| 664]/martes 2 febrero 1266 .

[25 rabǐ ||-5 ŷumảdà | 664]/primera mitad de febrero 1266 .

[16 ramaḍân 664]/21 junio 1266 . [ramaḍān 664]/junio 1266.

$[668-718] / 1270-1318$

Muere el sayyid Abū Zayd en Balvís.

[10 ramaḍan 668]/ 3 mayo 1270 .

Expulsión de los musulmanes murcianos. A su paso por Huercal Overa en dirección a Granada son asesinados.

673/julio 1274-junio 1275 .

Abū I-Hasan 'Alī sucede a Abū 'Abd Allāh Muhammad b. Hūd como rey de la Arrixaca en Murcia.

[3 ramaḍan 678]/7 enero 1280 .

Abū Ŷa áfar sucede a Abū I-Hasan como rey de la Arrixaca.

[678-694]/entre 1280 y 1290 .

Abū Ŷa $a^{c} f a r$ sucede a Abū I-Hasan como rey de la Arrixaca.

[678-694]/entre 1280 y 1295.

Abũ Isḥāq Ibrāhīm sucede a su padre Abū Ŷafar como rey de la Arrixaca.

[694-695]/a partir de 1295 hasta 1296.

Último señorío hūdí en el Levante: CreviIlente.

[718]/1318-19. 